\title{
Perbedaan Tahapan Pembelajaran Sekolah Lapang \\ Pengelolaan Tanaman Terpadu Padi Sawah antar Komunitas Petani di Lampung
}

\section{Difference of the Learning Stage Farmer Field School of Integrated Crops Management of Paddies Inter Community Farmers in Lampung}

\author{
Slameto $^{1}$, F. Trisakti Haryadi ${ }^{2}$, dan Subejo $^{2}$ \\ ${ }^{1}$ Balai Penelitian Tanaman Pangan, Bandar Lampung \\ ${ }^{2}$ Sekolah Pascasarjana, Universitas Gadjah Mada, Yogyakarta
}

\begin{abstract}
Enhancement of paddies production in Lampung done with implementation of agriculture technology innovation. The effort done with farmer field school of integrated crops management (FFS-ICM) of paddies. The learning of field school occured on various ethnic community of rice farmers. The effectivity of learning process can be occured with impersonation by the stages of attention, retention, behavior production process and motivation. The purpose of this study to analyze the difference effectiveness of learning farmer field school for farmers from ethnic Lampung, Java and Bali. The research methods with survey on rice farmers FFS-ICM of paddies participant. The sample total 286 farmers. The research located in Lampung. The research carried out Juni-September 2013. The data analysis done with the difference variance. The result indicate that only the motivate stages of process learning FFS-ICM between Bali-Java ethnic shows that the obvious difference. That implications need a preparation of learning material which capable to increase farmers motivation, need an improvement empowerment of farmers group, empowering figure roles and farmer society figures.
\end{abstract}

Keywords: stages of learning, farmer field school, paddies, Lampung-Bali-Java ethnic

\section{Abstrak}

Peningkatan produksi padi di Lampung dilakukan dengan implementasi inovasi teknologi pertanian melalui sekolah lapang pengelolaan tanaman terpadu (SL-PTT) padi sawah. Pembelajaran sekolah lapang tersebut terjadi pada berbagai komunitas etnis petani padi. Efektifitas proses pembelajaran dapat terjadi dengan peniruan melalui tahapan perhatian, pengingatan, pembentukan perilaku dan motivasi. Tujuan penelitian menganalisis perbedaan keefektifan pembelajaran sekolah lapang pengelolaan tanaman terpadu (SL-PTT) padi sawah petani etnis Lampung, Jawa dan Bali. Metode penelitian dengan survei pada petani peserta SL-PTT padi sawah. Jumlah sampel 286 petani. Lokasi penelitian di wilayah Provinsi Lampung. Waktu penelitian Juni-September 2013. Analisis data menggunakan uji beda varians. Hasil penelitian menunjukkan, pada proses pembelajaran tahapan motivasi petani antara etnis Bali-Jawa menunjukkan perbedaan nyata. Implikasinya diperlukan penyusunan materi pembelajaran yang mampu meningkatkan motivasi petani, diperlukan peningkatan pemberdayaan kelompok tani, pemberdayaan peran figur panutan dan tokoh masyarakat tani.

Kata kunci: tahap pembelajaran, sekolah lapang, padi, etnis Lampung-Bali-Jawa

\section{Pendahuluan}

Belajar merupakan suatu proses manusia untuk mencapai berbagai macam kompetensi, ketrampilan, dan sikap (Baharuddin dan Wahyuni, 2010; Basleman dan Mappa, 2011). Gagne dalam Dahar (2011) mengemukakan bahwa belajar sebagai suatu proses dimana pembelajar akan mampu merubah perilakunya sebagai akibat pengalaman. Dalam konteks ini, belajar semestinya harus mampu merubah sikap dan perilaku akibat

kompetensi, ketrampilan yang dapat berkembang. Hergenhahn dan Olson (2010) memberikan penekanan bahwa belajar bisa diukur dari perubahan dalam perilaku, perubahannya bisa relatif permanen, tidak terjadi secara langsung setelah selesai belajar, dapat berasal dari pengamatan dan pengalaman. Pembelajaran merupakan seperangkat tindakan yang dirancang untuk mendukung proses belajar. Dalam bahasa yang lain, Gagne (1985) menyatakan bahwa pembelajaran sebagai pengaturan peristiwa secara seksama dengan maksud agar terjadi belajar

${ }^{1}$ Korespondensi penulis 
dan membuatnya berhasil guna.

Belajar dapat terjadi melalui beberapa proses, salah satunya melalui proses pengamatan yang disebut sebagai belajar observasional. Proses belajar tersebut dimungkinkan berlangsung di masyarakat yang banyak terjadi interaksi di dalamnya. Di masyarakat tani, belajar observasional dapat mudah berlangsung. Keunggulan dari belajar observasional adalah bahwa pembelajar cukup dengan hanya mengamati hal-hal yang diobservasi, bisa diperkuat denganpengalamanlangsung maupun tidaklangsung. Agar belajar terlaksana dengan baik membutuhkan modeling yang mempunyai kompetensi yang tinggi. Petani anggota masyarakat yang menggunakan suatu inovasi (mengadopsi) dapat terjadi karena proses belajar melalui pengamatan terhadap yang dilakukan orang lain berkaitan inovasi yang disampaikan pada masyarakat tersebut.

Proses belajar observasional memiliki kaitan erat dengan bidang pertanian dimana secara alamiah aktivitas pertanian dapat diamati dan dialami oleh para petani dan stakeholders terkait. Salah satu daerah lumbung pangan yang memiliki fokus pembangunan bidang pertanian adalah Provinsi Lampung. Di Lampung, padi merupakan komoditas unggulan, namun produktivitasnya masih tergolong rendah yaitu 4,5 ton/ha (BPS, 2009). Menurut Dinas Pertanian Tanaman Pangan dan Hortikultura Provinsi Lampung (2011) pertumbuhan produksi padi sawah mencapai 5,24\%. Pada awal tahun 2011, Pemerintah telah memprogramkan peningkatan produksi nasional padi dari 68,80 juta ton gabah kering giling (GKG) menjadi 70,6 juta ton GKG. Untuk mendukung program tersebut, Provinsi Lampung meningkatkan target produksi padi dari 2,8 juta ton GKG menjadi 3,061 juta ton GKG (atau target meningkat 7\%). Untuk memenuhi target tersebut, salah satu upaya dilakukan dengan meningkatkan produk-tivitas padi dari 4,9 ton/ha menjadi 5,3 ton/ha GKG.

Pencapaian target pertumbuhan tersebut dapat ditempuh melalui penerapan berbagai pola kebijakan antara lain melalui perluasan areal tanam, penguatan kelembagaan dan dukungan finansial, peningkatan produktivitas padi dengan pendekatan PTT (Pengelolaan Tanaman Terpadu). PTT merupakan suatu pendekatan inovatif untuk meningkatkan produktivitas dan efisiensi usahatani melalui perbaikan pendekatan dalam perakitan paket teknologi padi dengan mengintegrasikan komponen teknologi yang bersifat sinergis, dilaksanakan secara parti-sipatif oleh petani serta penerapannya pada lokasi spesifik. Percepatan dan penyampaian inovasinya melalui pendekatan Sekolah Lapang Pengelolaan Tanaman Terpadu (SL-PTT). Jikalau dahulu pada pendekatan alih teknologi menjadikan petani peserta sebagai murid dan pemandu lapang sebagai guru, namun pada sekolah lapang tidak dibedakan antara guru dan murid, sehingga saling memberi pengetahuan yang diperoleh dari pengalaman.

Model pembelajaran yang terjadi dalam pendekatan sekolah lapang tersebut antara lain melalui pengamatan dan pengalaman langsung, dimana proses belajarnya berawal dari kegiatan belajar dan interaksi yang kemudian memberikan pengalaman pribadi petani, mengungkapkan pengalaman tersebut, menganalisis masalah yang terjadi, dan menyimpulkan hasil kegiatan yang dilakukan (Departemen Pertanian, 2008). Dalam pelaksanaan di lapangan, seringkali terjadi kendala teknis seperti belum dipahaminya pendekatan SL-PTT padi oleh para petani maupun sebagian petugas penyuluh dan pendamping. Inovasi yang disampaikan cenderung tidak sampai ke pengguna secara utuh, baik oleh para PPL sebagai penyampai inovasi maupun petani sebagai pengguna dan konsumen utama pada proses produksi.

Secara umum, di Lampung usahatani dilakukan pada agroekosistem lahan sawah dan lahan kering perkebunan. Komunitas petani yang berusahatani pada lahan sawah sebagian besar berasal dari etnis Lampung, Jawa, dan Bali. Sebaran dari keadaan tersebut terjadi karena daerah Lampung pernah merupakan daerah tujuan atau penempatan transmigrasi yang memungkinkan terjadinya akulturasi masyarakat pendatang dengan penduduk asli. Komunitas petani etnis Jawa keberadaannya merupakan masyarakat pendatang yang dimulai sejak era kolonisasi Pemerintahan Hindia Belanda, serta komunitas petani etnis Bali cenderung mempunyai kultur usahatani yang lebih mapan dibandingkan dengan komunitas petani etnis Lampung. Perbedaan kultur tersebut terjadi didasari pada usahatani lahan sawah yang dilakukan sejak jaman kerajaan, jaman penjajahan Belanda hingga saat ini, sehingga menimbulkan budaya berusahatani yang berbeda dengan masyarakat asli lokal yaitu 
petani etnis Lampung.

Proses belajar dalam teori kognitif sosial adalah proses belajar yang tidak langsung atau melalui proses observasi. Dalam teori kognitif sosial (Bandura, 1986), metode yang dipakai dalam belajar adalah dengan mengobservasi perilaku orang lain. Belajar melalui proses observasi adalah belajar respon baru dengan mengobservasi perilaku orang lain. Belajar dengan observasi berarti orang cenderung belajar secara pasif, yaitu tidak mengalami secara langsung, hanya melalui proses pengamatan. Penguatan (reinforcement) dalam proses belajar ini, diperoleh juga tidak langsung atau vicarious reinforcement (Schultz dan Schultz, 1994).

Bennet dan Murphy (1997) menjelaskan bahwa individu dapat membedakan, merencanakan secara aktif dan bekerja berdasarkan tujuan perilaku jangka panjang dan pendek. Tujuan individu tersebut didasarkan pada pilihan antara nilai-nilai yang berbeda, dari penguat perilaku dan hasil atau konsekuensi perilaku orang lain. Jadi tujuan dari perilaku individu dapat dipelajari melalui observasi perilaku orang lain. Bandura (1986) menyebut empat proses belajar observasional yaitu (1) proses perhatian (attention), (2) pengingatan (retention), (3) pembentukan perilaku (behavior production process), dan (4) motivasi (motivation).

Pada proses attention bahwa belajar adalah proses yang terus berlangsung, tetapi menunjukkan bahwa hanya yang diamati yang dapat dipelajari. Penguatan sebelumnya dapat menciptakan tata situasi perseptual dalam diri pengamat yang akan mempengaruhi observasi selanjutnya. Pada proses retention bahwa agar informasi yang sudah diperoleh dari observasi bisa berguna, informasi itu harus diingat atau disimpan, dimana informasi disimpan secara simbolis melalui dua cara, secara imajinal (imajinatif) dan secara verbal. Simbol-simbol yang disimpan secara imajinatif adalah gambaran tentang hal-hal yang dialami model, yang dapat diambil dan dilaksanakan lama sesudah belajar observasional terjadi. Pada behavior production process (proses pembentukan perilaku) menentukan sejauh mana hal-hal yang telah dipelajari akan diterjemahkan ke dalam tindakan atau performa. Seseorang mungkin mempelajari sesuatu secara kognitif namun dia tak mampu menerjemahkan informasi itu kedalam perilaku karena ada keterbatasan yang dibutuhkan untuk respons tertentu. Pada proses motivation, menurut teori Bandura bahwa penguatan memiliki dua fungsi utama. Pertama, ia menciptakan ekspektasi dalam diri pengamat bahwa jika mereka bertindak seperti model yang dilihatnya diperkuat untuk aktivitas tertentu, maka mereka akan diperkuat juga. Kedua, ia bertindak sebagai insentif untuk menerjemahkan belajar ke kinerja.

Studi-studi tentang pembelajaran telah dilakukan oleh para peneliti sesuai dengan bidang dan kompetensinya. Beberapa penelitian terdahulu menyangkut pembelajaran antara lain telah dilakukan oleh Hong et al. (2011) tentang pembelajaran kognitif sosial pada desain teknologi. Meskipun dasar teorinya sama, bedanya penelitian ini menekankan variabel jenis kelamin, ketrampilan, pengelolaan yang mempengaruhi pembelajaran dengan metode kualitatif Litt et al. (2002) meneliti pendugaan dari model pembelajaran sosial pada perilaku wanita lanjut usia, dengan variabel yang diteliti meliputi self efficacy, orientasi pemikiran, dukungan sosial dan kepatuhan individu dengan metode kuantitatif Subin et al. (2007) melakukan studi sifat dasar keinovatifan konsumen hubungan dengan perilaku adopsi produk baru dan peran intervensi pembelajaran sosial. Dalam kajian ini variabel yang diteliti meliputi karakteristik individu (umur, pendidikan, pendapatan) dan sifat keinovatifan terhadap perilaku adopsi. Fatemeh et al. (2011) melakukan pengujian teori Bandura di sekolah. Variabel yang dikaji meliputi pengalaman, persuasi, kondisi fisiologis, strategi mengajar, pengelolaan kelas terhadap self efficacy. Meskipun dasar teori yang dikaji belajar sosial tetapi obyek peneli-tiannya adalah siswa.

Penelitian tentang belajar sosial dan pemeliharaan variasi budaya (sebuah model evolusi di Afrika Timur) yang dilakukan oleh Elreath (2004). Pada penelitian ini variabel terikat adalah preferensi kepada teman, penghargaan kepada tokoh, prevalensi terhadap ilmu sihir dengan variabel bebas adalah umur, pendidikan, jenis kelamin, kemasyarakatan, kepemilikan ternak. Lam et al. (2010) meneliti tentang difusi orientasi pasar melalui organisasi (perspektif teori belajar sosial). Penelitian ini dasar teori adalah teori belajar sosial, obyek kajiannya tentang pemasaran.

Beberapa penelitian terdahulu tentang sekolah lapang telah dilakukan oleh Pailis (2006), George dan Edge (2011), Ali dan Haidar (2012) dan 
Pajwa et al. (2010) mengkaji peran budaya dalam pembelajaran petani dan adopsi teknologi (studi kasus sekolah lapang pada petani padi di Luzon, Filipina). Variabel yang diduga dalam penelitian ini umur, tingkat pendidikan, pengalaman bertani, luas lahan, jumlah tanggungan, status kepemilikan tanah, dan variabel budaya, norma, nilai-nilai. Dasar teorinya berupa pembelajaran kolektif; George dan Hegde (2011) meneliti tentang dampak sekolah lapang dalam membantu mempopulerkan penerapan PHT tanaman tomat. Variabel yang dianalisis adalah perubahan pengetahuan petani sebelum dan sesudah sekolah lapang, dengan komponen indikator berupa pengetahuan tentang: pembibitan, penumbuhan hama, langkah pengendalian hama, persiapan lahan, hama dan penyakit tanaman. Analisis dengan cara paired t-test sebelum dan sesudah sekolah lapang; Ali dan Haider (2012) melakukan analisis sekolah lapang sebagai sumber potensial dalam penyebarluasan teknologi antar petani di Faisalabad, Pakistan. Metode penelitan dengan survey dengan analisis secara deskriptif terhadap perubahan sikap dan pola pikir petani. Bajwa et al. (2010) melakukan kajian tentang analisis efektifitas metode penyuluhan melalui pendekatan sekolah lapang bagi petugas penyuluh pertanian di Punjab, India. Metode penyuluhan yang diuji meliputi demontrasi, diskusi kelompok, pemberian materi, leaflet, pameran, kampanye, papan slogan. Metode yang dilakukan dengan cara survey terhadap 3000 petani di 120 sekolah lapang. Analisis dilakukan secara deskriptif.

Rumusan masalah yang bisa dikemukakan bahwa komunitas etnis tertentu pada suatu masyarakat tani tersebut diidentifikasi mempunyai karakteristik tertentu yang menjadi sifat khas yang berbeda, yang dapat bersumber dari sifat pribadi seseorang, kondisi sosial, budaya, ekonomi, strata masyarakat dan sebagainya yang ada di suatu masyarakat yang sifatnya bervariasi. Tujuan dari penelitian ini adalah menganalisis perbedaan tahapan pembelajaran SL-PTT padi sawah yang dilakukan komunitas petani padi etnis Lampung, etnis Jawa dan etnis Bali yang tinggal di daerah Lampung.

\section{Metode Penelitian}

Penelitianinimenggunakanmetodedeskriptif yaitu suatu metode dalam meneliti status sekelompok manusia, obyek, kondisi, sistem pemikiran, ataupun kelas peristiwa pada masa sekarang yang bertujuan untuk membuat deskripsi, gambaran atau lukisan secara sistematis, faktual dan akurat mengenai faktafakta, sifat-sifat serta hubungan antara fenomena sesuai dengan tujuan yang ingin dicapai dalam kegiatan penelitian (Nazir, 2005). Desain penelitian berupa eksplanatory research dimana berusaha menjelaskan pengaruh antar variabel penelitian. Populasi penelitian ini adalah petani yang pernah mendapatkan pendampingan dan pembelajaran SL-PTT padi sawah tahun 2010-2011. Data yang dikumpulkan berupa data primer hasil wawancara petani dan data sekunder sebagai data pendukung yang sumbernya berasal dari instansi terkait sesuai tujuan penelitian.

Penelitian dilakukan di Provinsi Lampung meliputi Kabupaten Lampung Tengah, Lampung Selatan, dan Lampung Barat. Penentuan kabupaten, kecamatan, dan desa dilakukan secara purposive dan bertahap dengan mempertimbangan sebagai daerah sentra produksi padi, area sekolah lapang dan etnis tertentu. Demikian juga dalam penentuan desa yang mendasarkan pada syarat tersebut, dari kecamatan diambil 3 desa, dari masing-masing desa ditentukan kelompok belajar SL-PTT padi sawah. Lokasi ini ditentukan dengan pertimbangan: (1) merupakan sentra produksi padi sawah, (2) mendapatkan program SL-PTT padi sawah, (3) daerah sebaran komunitas etnis tertentu. Jangka waktu penelitian dilakukan pada bulan Juni-September 2013.

Unit penelitian yang menjadi objek adalah individu petani padi sawah. Jumlah keseluruhan responden adalah 286 petani meliputi: 96 orang petani padi sawah etnis Lampung di Kecamatan Pesisir Selatan Kabupaten Lampung Barat, 95 orang petani padi sawah etnis Bali di Kecamatan Seputih Raman Kabupaten Lampung Tengah, dan 95 orang petani padi sawah etnis Jawa di Kecamatan Candipuro Kabupaten Lampung Selatan. Sampel petani dipilih secara acak sederhana (simple random sampling) yang masing-masing etnis berasal dari 6 kelompok tani, 6 dusun, 3 desa per kabupaten.

Analisis perbedaan keefektifan proses pembelajaran SL-PTT padi sawah yang dilakukan komunitas petani padi (etnis Lampung, etnis Jawa dan etnis Bali) yang tinggal di Lampung dilakukan dengan Anova (analysis of varians). Tahapan analisisnya berupa uji homogenitas varians dengan 
melihat nilai Lavene statistik, untuk uji lanjut (post hoc tests) dilakukan dengan langkah sebagai berikut: (a) untuk varians yang sama (tidak berbeda nyata) dilakukan dengan uji Tukeys dan (b) untuk varians yang berbeda nyata dilakukan dengan uji GamesHowell.

\section{Hasil dan Pembahasan}

\section{Kondisi SL-PTT Padi Sawah di Lampung}

Situasi krisis pangan dunia yang berlangsung terus menerus mendapat perhatian serius dari pemerintah Indonesia. Peningkatan jumlah penduduk juga membutuhkan peningkatan pemenuhan kebutuhan pangan pokok beras. Dalam upaya memenuhi kebutuhan beras dari produksi dalam negeri maka pemerintah melalui Departemen Pertanian sejak tahun 2007 menggulirkan program peningkatan produksi beras nasional (P2BN), dimana pada waktu itu target peningkatan produksi beras sebanyak 2 juta ton produksi beras dan selanjutnya meningkat menjadi 5\% pertahun (Departemen Pertanian, 2008).

Peningkatan produksi beras melalui program P2BN tersebut diupayakan melalui peningkatan produktivitas padi dengan mengandalkan penerapan inovasi teknologi. Salah satu inovasi dalam upaya pencapaian target produksi adalah penerapan inovasi pengelolaan tanaman terpadu (PTT) padi sawah. Sejak dirintis tahun 2002, PTT telah mulai memasyarakat. Sejalan dengan implementasi P2BN, PTT menemukan momentum yang makin kuat, hal tersebut berbeda dengan program intensifikasi padi seperti Insus dan Supra Insus, dimana PTT bukan semata-mata sebagai suatu teknologi atau paket teknologi tetapi pendekatan dalam pemecahan masalah produksi di daerah setempat dengan menerapkan teknologi yang sesuai dan dipilih sendiri oleh petani. Kesimpulannya ialah bahwa pendekatan PTT ternyata mampu meningkatkan produktivitas dan efisiensi input produksi.

Mengacu dari pengalaman bahwa sekolah lapangpengendalianhamaterpadudapatmempercepat alih teknologi dan meredam serangan hama penyakit tanaman padi, serta ditindaklanjuti dengan pengembangan sekolah lapang iklim maka memberi inspirasi bagi pengembangan sistem belajar melalui sekolah lapang kepada masyarakat tani secara luas. Untuk itu dalam upaya pengembangan PTT secara nasional, atas inisiasi Departemen Pertanian maka pada tahun 2008 program Sekolah Lapang (SL) PTT diluncurkan. Manfaat yang dicapai dari adanya sekolah lapang adalah diseminasi inovasi PTT padi sawah cepat tersebar ke petani dalam upaya pencapaian target peningkatan produksi padi secara nasional.

Tahun 2010 luas areal SL-PTT padi sawah di Lampung meliputi luasan 47.593 Ha dengan komoditas padi inbrida dan 4.550 ha padi hibrida. Di Kabupaten Lampung Barat terdapat 10.000 ha areal SL yang tersebar pada 7 kecamatan, 56 desa, 216 kelompok tani. Kabupaten Lampung Tengah terdapat 15.500 ha areal SL yang tersebar pada 13 kecamatan, 89 desa, 336 kelompok tani. Di Kabupaten Lampung Selatan ini terdapat 9.000 ha areal SL yang tersebar pada 7 kecamatan, 85 desa, 216 kelompok tani (BPTP Lampung 2010). Pada tahun 2011, luas areal SL-PTT padi sawah di seluruh Provinsi Lampung meningkat menjadi 120.700 ha padi inbrida dan 10.500 ha padi hibrida. Tahun 2012 luasan SL-PTT padi sawah di Lampung meliputi 100.725 ha padi inbrida meliputi 127 kecamatan, 981 desa, 4.004 kelompok tani. Tahun 2013 luasan SLPTT di Lampung meliputi 161.275 ha padi inbrida yang tersebar di 220 kecamatan, 1.717 desa, 6.409 kelompok tani, sedangkan SL-PTT padi hibrida pada tahun yang sama meliputi 69 kecamatan, 232 desa, 458 kelompok tani sasaran dengan luas 9.000 ha.

Komoditas padi sawah yang dilakukan diseminasi melalui program sekolah lapang pengelolaan tanaman terpadu padi sawah meliputi padi sawah jenis inbrida maupun hibrida. Jenis padi tersebut diintroduksikan kepada masyarakat tani dengan tujuan selain untuk mengatasi berbagai kendala yang seringkali ditemukan di lapangan (hama, penyakit, kesuburan) juga bermaksud agar lebih cepat diadopsi dan ditanam sehingga diharapkan produksi padi petani semakin meningkat. Varietas padi inbrida yang diintroduksikan kepada petani cukup banyak dan bervariasi sesuai dengan kondisi spesifik lokasi dan keunggulan agroekosistem wilayahnya, varietasnya antara lain: Ciherang, Cigeulis, Mekongga, IR-64, Cilamaya Muncul, Ciliwung, Pandanwangi, Situbagendit, Inpari 7, Inpari 10, Inpari 13 dan sebagainya.

Beberapa kajian tentang produksi padi terkait sekolah lapang PTT padi sawah telah banyak dilakukan 
Tabel 1 Distribusi Petani Menurut Umur dan Pendidikan per Etnis di Lampung

\begin{tabular}{|c|c|c|c|c|c|c|c|c|c|}
\hline \multirow{2}{*}{ No } & \multirow{2}{*}{ Kategori } & \multicolumn{2}{|c|}{$\begin{array}{l}\text { Etnis Lampung } \\
\qquad(\mathrm{n}=96)\end{array}$} & \multicolumn{2}{|c|}{$\begin{array}{c}\text { Etnis Jawa } \\
(\mathrm{n}=95)\end{array}$} & \multicolumn{2}{|c|}{$\begin{array}{c}\text { Etnis Bali } \\
(\mathrm{n}=95)\end{array}$} & \multicolumn{2}{|c|}{$\begin{array}{c}\text { Total Petani } \\
(\mathrm{n}=\mathbf{2 8 6})\end{array}$} \\
\hline & & $\begin{array}{l}\text { Jumlah } \\
\text { (orang) }\end{array}$ & $\%$ & $\begin{array}{l}\text { Jumlah } \\
\text { (orang) }\end{array}$ & $\%$ & $\begin{array}{l}\text { Jumlah } \\
\text { (orang) }\end{array}$ & $\%$ & $\begin{array}{l}\text { Jumlah } \\
\text { (orang) }\end{array}$ & $\%$ \\
\hline A. & Umur (tahun) & & & & & & & & \\
\hline 1. & $18-30$ & 17 & 17,71 & 12 & 12,63 & 8 & 8,42 & 37 & 12,93 \\
\hline 2. & $31-55$ & 69 & 72,92 & 77 & 81,05 & 67 & 69,47 & 213 & 74,47 \\
\hline 3. & $>55$ & 9 & 9,37 & 6 & 6,32 & 21 & 22,11 & 36 & 12,60 \\
\hline B. & Pendidikan & & & & & & & & \\
\hline 1. & SD & 44 & 45,83 & 43 & 45,26 & 18 & 18,95 & 105 & 36,71 \\
\hline 2. & SLTP & 23 & 23,96 & 30 & 31,58 & 18 & 18,95 & 71 & 24,83 \\
\hline 3. & SLTA & 20 & 20,83 & 20 & 21,05 & 46 & 48,42 & 86 & 30,07 \\
\hline 4. & PT & 9 & 9,38 & 2 & 2,11 & 13 & 13,68 & 24 & 8,39 \\
\hline
\end{tabular}

penelitian. Di Lampung rata-rata peningkatan produktivitas padi sawah jenis padi inbrida pada areal SL-PTT rata-rata $11,59 \%$ lebih tinggi dibanding Non SL-PTT. Demikian juga rata-rata peningkatan produktivitas jenis padi hibrida areal SL-PTT 13,70\% lebih tinggi dibanding Non SLPTT (BPTP Lampung 2010). Kajian yang dilakukan oleh Pujiharti et al. (2008) menemukan bahwa PTT padi apabila diintegrasikan dengan pemeliharaan ternak untuk menambah kebutuhan pupuk tanaman padi mampu meningkatkan produktivitas padi sebesar $16,67-33,50 \%$.

\section{Karakteristik Petani Peserta SL-PTT Padi Sawah}

Berdasarkan hasil pengukuran diketahui distribusi umur dan pendidikan petani di lokasi penelitian dengan rincian seperti pada Tabel 1. Dalam penelitian ini pembagian umur dikelompokkan menjadi 3 kelompok umur atas dasar sebarannya. Menurut WHO pembagian umur dapat dibagi atas dasar tingkat kedewasaan pada rentang usia 15-an tahun sampai 50-an tahun. Rentang usia antara usia dewasa muda dan dewasa tua sekitar 30-an tahun (Notoatmodjo, 2003). Berbeda dengan pendapat tersebut, menurut BPS penduduk berumur di atas 65 tahun dianggap sudah tidak produktif lagi, sedangkan penduduk yang berumur 15-65 tahun disebut berada pada usia kerja dan masih produktif (Pudjianto, 2009), sedangkan pada penelitian ini,
Pembagian umur meliputi 18-30 tahun, 31-55 tahun, dan $>55$ tahun.

Umur berkaitan dengan kemampuan fisik seseorang. Umur sering digunakan untuk melihat produktivitas tenaga kerja, angkatan kerja dan proporsi penduduk berusia produktif dalam suatu kegiatan tertentu. Pada ketiga etnis petani sebagian besar yaitu etnis Lampung (72,92\%), etnis Jawa $(81,05 \%)$, etnis Bali $(69,47 \%)$ berada pada kisaran umur 31-45 tahun yang berarti berada pada kisaran umur produktif. Hal ini akan akan berkaitan dengan proses pembelajaran SL-PTT padi sawah. Selain itu dalam mengikuti SL-PTT padi sawah tidak ada petani yang mempunyai umur dibawah 18 tahun.

Dalam penelitian ini, tingkat pendidikan petani dikelompokkan kedalam empat kategori, yaitu dasar, menengah, tinggi. Pendidikan nelayan yang digolongkan kedalam kategori dasar adalah petani tamat SD dan SLTP Untuk kategori menengah adalah tamat SLTA. Untuk kategori tinggi meliputi tamat perguruan tinggi. Tabel 1 menunjukkan bahwa pendidikan petani pada umumnya masih pada pada pendidikan dasar. Petani etnis Lampung tamat SD 45,83\%, tamat SLTP 23,96\%, petani etnis Jawa tamat SD 45,26\%, tamat SLTP 31,58\%, sedangkan etnis Bali dominan berpendidikan menengah dimana $48,42 \%$ tamat SLTA dan hanya $18,95 \%$ tamat SD dan 18,95\% tamat SLTP. Kondisi tingkat pendidikan petani tersebut mempengaruhi daya tangkap dan keberhasilan dalam pembelajaran SL-PTT padi sawah pada ketiga etnis petani. 
Tabel 2 Distribusi Pengalaman Bertani Padi Sawah Pada Beberapa Etnis di Lampung

\begin{tabular}{|c|c|c|c|c|c|c|c|c|c|c|}
\hline \multirow{3}{*}{ No } & \multirow{3}{*}{ Kategori } & \multirow{3}{*}{$\begin{array}{c}\text { Kisaran } \\
\text { pengalaman } \\
\text { (tahun) }\end{array}$} & \multicolumn{8}{|c|}{ Pengalaman bertani } \\
\hline & & & \multicolumn{2}{|c|}{$\begin{array}{c}\text { Etnis Lapung } \\
(\mathbf{n}=96)\end{array}$} & \multicolumn{2}{|c|}{$\begin{array}{c}\text { Etnis Jawa } \\
\qquad(\mathrm{n}=95)\end{array}$} & \multicolumn{2}{|c|}{$\begin{array}{c}\text { Etnis Bali } \\
(\mathrm{n}=95)\end{array}$} & \multicolumn{2}{|c|}{$\begin{array}{l}\text { Total Petani } \\
\qquad(\mathrm{n}=\mathbf{2 8 6})\end{array}$} \\
\hline & & & $\begin{array}{c}\text { Jml. } \\
\text { (orang) }\end{array}$ & $\%$ & $\begin{array}{c}\text { Jml. } \\
\text { (orang) }\end{array}$ & $\%$ & $\begin{array}{c}\text { Jml. } \\
\text { (orang) }\end{array}$ & $\%$ & $\begin{array}{c}\text { Jml. } \\
\text { (orang) }\end{array}$ & $\%$ \\
\hline 1. & Rendah & $0-22$ & 64 & 66,67 & 69 & 72,63 & 55 & 57,89 & 188 & 65,73 \\
\hline 2. & Sedang & $23-44$ & 28 & 29,17 & 24 & 25,26 & 33 & 34,74 & 85 & 29,72 \\
\hline 3. & Tinggi & $45-66$ & 4 & 4,16 & 2 & 2,11 & 7 & 7,37 & 13 & 4,55 \\
\hline \multicolumn{2}{|c|}{ Jumlah: } & & 96 & 100,00 & 95 & 100,00 & 95 & 100,00 & 286 & 100,00 \\
\hline
\end{tabular}

Sumber: Analisa Data Primer, 2013

Hampir seluruh petani dari ketiga etnis termasuk dalam petani yang berpengalaman rendah dalam usahatani padi (kurang dari 23 tahun). Distribusi pengalaman bertani untuk etnis Lampung bahwa $66,67 \%$ petani berada pada kategori rendah, dan $29,17 \%$ petani pada kategori sedang, untuk etnis Jawa bahwa $72,63 \%$ petani berada pada kategori rendah, dan 25,26\% petani pada kategori sedang, sedangkan untuk etnis Bali bahwa $57,89 \%$ petani berada pada kategori rendah, dan $34,74 \%$ petani pada kategori sedang. Hal tersebut menunjukkan bahwa petani cenderung masih rendah pengalaman usahatani.

Jumlah tanggungan keluarga dalam suatu rumah tangga merupakan beban dalam penyediaan segala kebutuhan hidup, disisi lain merupakan sumber tenaga kerja dalam melaksanakan kegiatan usahatani padi sawah. Secara keseluruhan petani $(\mathrm{n}=286)$ menunjukkan bahwa sebagian besar petani $(55,24 \%)$ mempunyai jumalh tanggungan keluarga pada kategori sedikit. Tetapi apabila dilihat distribusinya untuk masing masing etnis petani dapat dikemukakan sebagai berikut, pada petani etnis Lampung sebagian besar petani mempunyai jumlah tanggungan keluarga berkisar 5-8 orang dan berada pada kategori tanggungan sedang, petani etnis Jawa sebagian besar petani mempunyai jumlah tanggungan keluarga maksimal 4 orang dan berada pada kategori tanggungan sedikit, petani etnis Bali sebagian besar petani juga mempunyai jumlah tanggungan keluarga maksimal 4 orang dan berada pada kategori tanggungan sedikit. Kondisi tersebut akan mempengaruhi jumlah pengeluaran dari rumah tangga petani karena semakin banyak jumlah anggota keluarga maka akan semakin banyak pengeluaran yang dibutuhkan. Tetapi disisi lain apabila anggota keluarga petani berada pada usia produktif akan berpotensi sebagai sumber tenaga kerja keluarga yang justru akan membantu dalam penerimaan rumah tangga petani.

Jumlah tenaga kerja produktif dalam keluarga petani pada masing-masing etnis sebagian besar mempunyai tenaga kerja produktif kategori sedikit ( $\leq 4$ orang) dalam rumah tangganya. Pada keluarga petani etnis Lampung, 91,67\% petani mempunyai tenaga produktif dengan jumlah sedikit, 98,95\% petani etnis Jawa mempunyai tenaga produktif dengan jumlah sedikit, dan pada etnis Bali 96,85\% petani mempunyai tenaga produktif dengan jumlah sedikit. Kondisi tersebut akan mempengaruhi jumlah ketersediaan tenaga kerja dari rumah tangga petani karena semakin banyak jumlah anggota keluarga yang produktif maka akan semakin membantu dalam penerimaan rumah tangga petani atau minimal membantu dalam berusahatani keluarga.

Sebagian besar petani mempunyai pekerjaan tambahan dalam rumah tangganya, hal tersebut akan mempengaruhi jumlah penerimaan dari rumah tangga petani. Tetapi disisi lain akan berpengaruh terhadap pembagian kerja petani dalam melakukan usahatani utama yaitu bertanam padi sawah bahkan mengganggu pekerjaan utama bertani. Distribusi jenis pekerjaan sambilan dari petani sawah pada etnis Lampung, Jawa, dan Bali yang berada di Lampung di sajikan pada Tabel 3.

\section{Perbedaan Proses Pembelajaran SL-PTT Padi Sawah antar Etnis Petani}

Data pada Tabel 4, dapat memperlihatkan 
Tabel 3 Distribusi Jenis Pekerjaan Sambilan dari Petani Padi Sawah pada Beberapa Etnis di Lampung

\begin{tabular}{|c|c|c|c|c|c|c|c|c|c|}
\hline \multirow{3}{*}{ No } & \multirow{3}{*}{$\begin{array}{c}\text { Jenis pekerjaan } \\
\text { sampingan }\end{array}$} & \multicolumn{8}{|c|}{ Jumlah tanggungan keluarga petani } \\
\hline & & \multicolumn{2}{|c|}{$\begin{array}{l}\text { Etnis Lampung } \\
\qquad(\mathrm{n}=96)\end{array}$} & \multicolumn{2}{|c|}{$\begin{array}{l}\text { Etnis Jawa } \\
\qquad(\mathrm{n}=95)\end{array}$} & \multicolumn{2}{|c|}{$\begin{array}{c}\text { Etnis Bali } \\
(\mathbf{n}=95)\end{array}$} & \multicolumn{2}{|c|}{$\begin{array}{c}\text { Total Petani } \\
(\mathrm{n}=\mathbf{2 8 6})\end{array}$} \\
\hline & & $\begin{array}{l}\text { Jml. } \\
\text { (orang) }\end{array}$ & $\%$ & $\begin{array}{c}\text { Jml. } \\
\text { (orang) }\end{array}$ & $\%$ & $\begin{array}{c}\text { Jml. } \\
\text { (orang) }\end{array}$ & $\%$ & $\begin{array}{c}\text { Jml. } \\
\text { (orang) }\end{array}$ & $\%$ \\
\hline 1. & Memelihara ternak & 2 & 2,08 & 8 & 8,42 & 32 & 33,68 & 42 & 14,68 \\
\hline 2. & Berkebun & 31 & 32,29 & 1 & 1,05 & 0 & 0,00 & 32 & 11,19 \\
\hline 3. & Nelayan & 1 & 1,04 & 0 & 0,00 & 0 & 0,00 & 1 & 0,35 \\
\hline 4. & Buruh tani & 5 & 5,21 & 12 & 12,63 & 9 & 9,47 & 26 & 9,09 \\
\hline 5. & Memelihara ikan & 0 & 0,00 & 0 & 0,00 & 6 & 6,32 & 6 & 2,09 \\
\hline 6. & $\begin{array}{l}\text { Warung/kios/ } \\
\text { berdagang }\end{array}$ & 7 & 7,29 & 15 & 15,79 & 4 & 4,21 & 26 & 9,09 \\
\hline 7. & Tukang & 2 & 2,08 & 3 & 3,13 & 0 & 0,00 & 5 & 1,75 \\
\hline 8. & Bengkel & 0 & 0,00 & 0 & 0,00 & 1 & 1,18 & 1 & 0,35 \\
\hline 9. & Penjahit & 0 & 0,00 & 0 & 0,00 & 1 & 1,18 & 1 & 0,35 \\
\hline 10. & Angkutan (sopir) & 0 & 0,00 & 0 & 0,00 & 1 & 1,18 & 1 & 0,35 \\
\hline 11. & Mengajar & 3 & 3,13 & 0 & 0,00 & 0 & 0,00 & 3 & 1,05 \\
\hline 12. & Pamong & 2 & 2,08 & 2 & 2,08 & 0 & 0,00 & 4 & 1,40 \\
\hline 13. & Wiraswasta & 11 & 11,46 & 15 & 15,79 & 5 & 5,26 & 31 & 10,84 \\
\hline 14. & Tidak menjawab & 32 & 33,33 & 39 & 41,05 & 36 & 37,89 & 107 & 37,41 \\
\hline Total & & 96 & 100,00 & 95 & 100,00 & 95 & 100,00 & 286 & 100,00 \\
\hline
\end{tabular}

distribusi petani menurut kategori pada efektifitas proses pembelajaran yang dilakukan beberapa etnis petani di Lampung. Distribusi efektifitas proses pembelajaran dikelompokkan menjadi 3 kategori yaitu rendah, sedang, dan tinggi. Nilai skala minimal skor efektifitas proses pembelajaran berdasarkan skala Likert adalah 0 dan nilai skala maksimal adalah 4. Jumlah pertanyaan atau pernyataan untuk menggali proses pembelajaran sebanyak 37 butir maka total skor minimal yang bisa dicapai adalah 0 dan total skor maksimal yang bisa dicapai adalah 148. Berdasarkan skor minimal dan skor maksimal maka kategori efektifitas proses pembelajaran tersebut adalah: (a) kategori rendah: skor 0-48; (b) kategori sedang: skor 49-98; dan (c) kategori tinggi: skor 99-148.

Dari Tabel 4 menunjukkan efektifitas proses pembelajaran masing-masing etnis petani padi di Provinsi Lampung tergolong sedang yaitu $62,50 \%$ petani etnis Lampung, 68,42\% petani etnis Jawa dan $80 \%$ petani etnis Bali. Ini mengindikasikan bahwa dalam pembelajaran SL-PTT padi sawah bagi semua etnis bisa dikatakan cukup berhasil dalam proses pembelajaran yang dilakukan.

Hasil analisis perbedaan proses pembelajaran SL-PTT padi sawah yang dilakukan terhadap masyarakat petani etnis Lampung, menunjukkan bahwa nilai Lavene statistik baik pada variabel proses pembelajaran SL-PTT padi sawah secara keseluruhan maupun nilai pada masing-masing tahapan proses pembelajaran adalah signifikan (nyata). Hal tersebut berarti nilai varians pada variabel proses pembelajaran SL PTT padi sawah secara keseluruhan (nilai Lavene $=3,223$ dengan nilai sig. $\alpha=5 \%$ ) maupun nilai pada masing-masing tahapan proses pembelajaran yang meliputi tahap perhatian (nilai Lavene $=2,651$ dengan nilai sig. $\alpha$ $=10 \%$ ), pengingatan (nilai Lavene $=3,164$ dengan nilai sig. $\alpha=5 \%$ ), pembentukan perilaku (nilai Lavene $=7,626$ dengan nilai sig. $\alpha=1 \%$ ), dan motivasi (nilai Lavene $=5,657$ dengan nilai sig. $\alpha=$ $1 \%)$ mempunyai nilai varians yang berbeda nyata. Sebaliknya nilai uji $\mathrm{F}$ pada anova pada variabel proses pembelajaran SL-PTT padi sawah secara keseluruhan tidak menunjukkan perbedaan yang nyata, yang berarti pada uji pembandingan tersebut 
Tabel 4 Distribusi petani menurut kategori proses pembelajaran

\begin{tabular}{|c|c|c|c|c|c|c|c|c|c|c|}
\hline \multirow{3}{*}{ No } & \multirow{3}{*}{ Kategori } & \multirow{3}{*}{ Skor } & \multicolumn{8}{|c|}{ Efektifitas proses pembelajaran } \\
\hline & & & \multicolumn{2}{|c|}{$\begin{array}{l}\text { Etnis Lampung } \\
\quad(n=96)\end{array}$} & \multicolumn{2}{|c|}{$\begin{array}{c}\text { Etnis Jawa } \\
(\mathbf{n}=\mathbf{9 5})\end{array}$} & \multicolumn{2}{|c|}{$\begin{array}{c}\text { Etnis Bali } \\
(\mathbf{n}=95)\end{array}$} & \multicolumn{2}{|c|}{$\begin{array}{c}\text { Total Petani } \\
(n=286)\end{array}$} \\
\hline & & & $\begin{array}{c}\text { Jml. } \\
\text { (orang) }\end{array}$ & $\%$ & $\begin{array}{l}\text { Jml. } \\
\text { (orang) }\end{array}$ & $\%$ & $\begin{array}{l}\text { Jml. } \\
\text { (orang) }\end{array}$ & $\%$ & $\begin{array}{c}\text { Jml. } \\
\text { (orang) }\end{array}$ & $\%$ \\
\hline 1. & Rendah & $0-48$ & 8 & 8,33 & 2 & 2,11 & 5 & 5,26 & 15 & 5,24 \\
\hline 2. & Sedang & $49-98$ & 60 & 62,50 & 65 & 68,42 & 76 & 80,00 & 201 & 70,28 \\
\hline 3. & Tinggi & $99-148$ & 28 & 29,17 & 28 & 29,47 & 14 & 14,74 & 70 & 24,48 \\
\hline \multicolumn{2}{|c|}{ Jumlah: } & & 96 & 100,00 & 95 & 100,00 & 95 & 100,00 & 286 & 100,00 \\
\hline
\end{tabular}

secara umum ketiga etnis tidak berbeda nyata dalam proses pembelajaran SL-PTT padi sawah. Namun demikian apabila dilihat nilai anova per masingmasing tahapan proses pembelajaran hanya motivasi yang menunjukkan nilai $\mathrm{F}$ yang signifikan pada $\alpha$ $=10 \%$ ), yang berarti hanya tahapan motivasi yang berbeda pada proses pembelajaran SL-PTT padi sawah. Hal tersebut memperjelas dalam mengetahui pada posisi apa masing-masing etnis petani melakukan pembelajaran SL-PTT padi sawah.

Hasil analisis uji lanjut (post hoc tests) untuk melihat perbedaan proses pembelajaran SLPTT padi sawah maupun tahapan pembelajaran antar masing-masing etnis diperoleh hasil bahwa hanya tahapan motivasi antara etnis Bali-Jawa yang menunjukkan nilai berbeda nyata (nilai uji Games-Howell $=-2,2947$ dengan nilai $\alpha=10 \%$ ). Hal tersebut mengindikasikan bahwa motivasi pada proses pembelajaran antara etnis Bali dan etnis Jawa berbeda, dimana nilai motivasi etnis Jawa lebih tinggi dibanding etnis Bali dalam pembelajaran SL-PTT padi sawah dengan rata-rata perbedaan nilai skor motivasi yang lebih tinggi yakni 2,2947. Kenyataan di lapangan menunjukkan perbedaan tersebut terjadi terutama pada motivasi (a) untuk memproduksi padi yang lebih tinggi, (b) motivasi untuk mendapatkan manfaat yang lebih banyak dari pembelajaran SL-PTT padi sawah, (c) motivasi untuk mendapatkan keuntungan yang tinggi, (d) motivasi untuk memperbaiki kualitas hasil produksi yang lebih baik, (e) motivasi agar mudah memasarkan produksi padi sawah dan untuk mendapatkan harga jual produk yang tinggi, (f) motivasi agar kelestarian kesuburan tanah dan air lebih terjamin, serta $(\mathrm{g})$ motivasi untuk mendapatkan nilai tambah usahatani yang lebih tinggi.

\section{Kesimpulan}

Tahapan motivasi petani antara etnis Bali-Jawa menunjukkan perbedaan nyata pada proses pembelajaran sekolah lapang pengelolaan tanaman terpadu padi sawah, sedangkan tahapan pengamatan, pengingatan, dan pembentukan perilaku tidak menunjukkan perbedaan antara petani etnis Lampung-Jawa, etnis Lampung-Bali, maupun etnis Jawa-Bali dalam proses pembelajaran sekolah lapang.

Melihat empat tahapan proses pembelajaran hanya tahap motivasi yang membedakan antar etnis petani untuk itu materi dalam pembelajaran dapat disusun untuk meningkatkan motivasi petani, metode pembelajaran yang ada dapat dilakukan lebih baik lagi demi mempertahankan pembelajaran pada tahap perhatian, tahap pengingatan, dan pembentukan perilaku pembelajar.

\section{Daftar Pustaka}

Ali M, Haider MS. 2012. An Analysis of farmer Field School As A Potential Source of Advanced Technology Dissemination Among The farmers of District Faisalabad, Pakistan. OIDA International Journal of Sustainable Development 03(01).

Badan Pusat Statistik Lampung. 2009. Lampung Dalam Angka. Bandar Lampung (ID): BPS Provinsi Lampung.

Baharuddin dan Wahyuni EN. 2010. Teori Belajar dan Pembelajaran. Penerbit Ar-Ruzz Media. Yogyakarta (ID).

Bajwa MS, Ahmad M. Ali T. 2010. An Analysis of Effectiveness of Extension Methods Used in 
Farmers Field School Approach for Agricultural Extension Work in Punjab, Pakistan. J Agric. Res. 48(2).

Bandura A. 1986. Social Foundations of Thoughtand Action: A Social Cognitive Theory. Prentice Hall, Englewood Cliffs. New Jersey.

Basleman A, Mappa S. 2011. Teori Belajar Orang Dewasa. Penerbit PT. Remaja Rosdakarya. Bandung (ID).

Bennett P, Murphy S. 1997. Psychology and Health

Promotion. Buchingham: Open University Press.

BPTP Lampung. 2010. Diseminasi Pengelolaan

Tanaman Terpadu Mendukung Program P2BN. Laporan Tahunan. Balai Pengkajian Teknologi Pertanian Lampung. Bandar Lampung (ID).

BPTP Lampung. 2011. Pendampingan Teknologi

SLPTT Padi dan Jagung. Balai Pengkajian Teknologi Pertanian Lampung. Bandar Lampung (ID).

Dahar RW. 2011. Teori-Teori Belajar dan Pembelajaran. Jakarta (ID): Penerbit Erlangga.

Departemen Pertanian. 2008. Panduan Pelaksanaan

Sekolah Lapang Pengelolaan Tanaman Terpadu (SL-PTT) Padi. Jakarta (ID): Departemen Pertanian Republik Indonesia.

Dinas Pertanian Tanaman Pangan dan Hortikultura

Provinsi Lampung. 2013. Laporan CP/CL, BLBU SLPTT. Bandar Lampung (ID): Dinas Pertanian Tanaman Pangan dan Hortikultura Provinsi Lampung.

Dinas Pertanian Tanaman Pangan dan Hortikultura

Provinsi Lampung. 2011. Laporan Tahunan. Bandar Lampung (ID): Dinas Pertanian Tanaman Pangan dan Hortikultura Provinsi Lampung.

Elreath R. 2004. Social Learning and The Maintenance of Cultural Variation: An Evolutionary Model and Data from East Africa. Journal American Anthropologist. 106(2): 308321.

Fatemeh S, Mohamadi, Asadzadeh H, Ahadi H, Jomehri F, 2011. "Testing Bandura's Theory in School". Procedia Social and Behavioral Sciences, 12(2011): 426-435. [Internet]. [dapat diunduh dari: http://www.Science Direct.com].

Gagne ED. 1985. The Cognitive Psychology of School Learning. Little Brown. Boston.

George S, Hegde MR. 2011. "Impact of Farmer Field School in Popularization of IPM Practices in Tomato Cultivation". Agric.Sci.Digest. 31 (2): 116-120.

Hergenhahn BR, Olson MH. 2010. Theories of Learning (Teori Belajar). Jakarta (ID): Penerbit Kencana.

Hong, Chao J, Hwang MY, Wong WT, Lin HC, Yau CM, 2011. "Gender Differences in Social Cognitive Learning at a Technological Project Design". Int. J. Technol. Des. Educ. DOI 10.1007/s10798-011-9152-x.

Lam K, Son, Kraus F, Ahearne M, 2010. "The Diffusion of Market Orientation Throughout the Organization: A Social Learning Theory Perspective". Journal of Marketing (September 2010) :61-79.

Litt MD, Kleppinger A, Judge JO. 2002. Initiation and Maintenance of Exercise Behavior in Older Women Predictors from The Social Learning Model. Journal of Behavioral Medicine .25(1): February 2002.

Nazir M. 2005. Metode Penelitian. Jakarta (ID): Penerbit Ghalia.

Notoatmodjo. 2003. Pembagian Umur. Universitas Pembangunan Nasional Veteran. [Internet]. [dapat diunduh dari: http://www.library. upnvj. ac.id].

Pailis FG. 2006. The Role of Culture in Farmer Learning and Technology Adoption: A Case Study of Farmer Field Schools Among Rice Farmers in Central Luzon, Philippines. Journal Agriculture and Human Values (2006) 23: 491500 .

Pudjianto K. 2009. Partisipasi Masyarakat Dalam Rehabilitasi Hutan, Lahan Dan Konservasi Sumberdaya Air Di Sub DAS Keduang, Daerah Hulu DAS Bengawan Solo, [tesis]. Bogor (ID): Institiut Pertanian Bogor.

Pujiharti Y, Muchlas, Ernawati, Wijayanto B. 2008. Kajian Penerapan Pengelolaan Tanaman Terpadu (PTT) Padi Sawah di Lampung. Prosiding Seminar Penelitian dan Pengembangan Teknologi Pertanian Spesifik Lokasi. Balai Besar Pengkajian dan Pengembangan Teknologi Pertanian kerjasama dengan Perhiptani Lampung serta Dinas Pertanian dan Ketahanan Pangan Provinsi Lampung. Bandar Lampung. Schultz D, Schultz SE.1994. Theories of Personality. California: Brooks Cole Publishing Company. Subin In, Mason CH, Houston MB. 2007. Does 
Jurnal Penyuluhan, Maret 2015 Vol. 11 No. 1

Innate Consumer Innovativeness Relate to New Product/Service Adoption Behavior?

The Intervening Role of Social Learning Via Vicarious Innovativeness. Journal of the Academy of Marketing Science (2007) 35:6375. 